\title{
Metabolic pathways of the wheat (Triticum aestivum) endosperm amyloplast revealed by proteomics Frances M Dupont
} Address: Western Regional Research Center, United States Department of Agriculture, Agricultural Research Service, 800 Buchanan Street, Albany,
CA $94710 K$, USA

Email: Frances M Dupont - frances.dupont@ars.usda.gov

Published: 17 April 2008

BMC Plant Biology 2008, 8:39 doi:10.1 186/147|-2229-8-39

This article is available from: http://www.biomedcentral.com/I47I-2229/8/39

(C) 2008 Dupont; licensee BioMed Central Ltd.

This is an Open Access article distributed under the terms of the Creative Commons Attribution License (http://creativecommons.org/licenses/by/2.0), which permits unrestricted use, distribution, and reproduction in any medium, provided the original work is properly cited.
Received: 9 July 2007

Accepted: 17 April 2008

\begin{abstract}
Background: By definition, amyloplasts are plastids specialized for starch production. However, a proteomic study of amyloplasts isolated from wheat (Triticum aestivum Butte 86) endosperm at 10 days after anthesis (DPA) detected enzymes from many other metabolic and biosynthetic pathways. To better understand the role of amyloplasts in food production, the data from that study were evaluated in detail and an amyloplast metabolic map was outlined.
\end{abstract}

Results: Analysis of 288 proteins detected in an amyloplast preparation predicted that 178 were amyloplast proteins. Criteria included homology with known plastid proteins, prediction of a plastid transit peptide for the wheat gene product or a close homolog, known plastid location of the pathway, and predicted plastid location for other members of the same pathway. Of these, 135 enzymes were arranged into 18 pathways for carbohydrate, lipid, amino acid, nucleic acid and other biosynthetic processes that are critical for grain-fill. Functions of the other proteins are also discussed.

Conclusion: The pathways outlined in this paper suggest that amyloplasts play a central role in endosperm metabolism. The interacting effects of genetics and environment on starch and protein production may be mediated in part by regulatory mechanisms within this organelle.

\section{Background}

Wheat grains are a major source of human food. Desirable grain-fill traits for bread wheat include high rates of starch production for yield, and high protein content for breadmaking. However, there is an undesirable trade-off between yield and protein content that is determined by genetics and environment [1-5]. A better understanding of the role of the amyloplast in endosperm metabolism may help to understand and ameliorate this trade-off [6].

Some aspects of the regulation of starch and protein accumulation in cereal grains are understood. Prior to the grain-fill stage, yield is increased by increasing the number of tillers, heads and kernels through genetics, fertilization and water supply. During grain-fill, yield is determined largely by starch accumulation. Starch accumulation appears to be mainly sink-limited, whereas protein accumulation is source-limited [7-9]. Manipulation of the sucrose supply to the grain does not have a big effect on starch accumulation, and $\mathrm{CO}_{2}$ fixation apparently is more than adequate to maintain good rates of grain-fill. In contrast, the nitrogen supply greatly affects protein accumulation and kernels are flexible in the amount of nitrogen and the amount and type of protein that is accumulated [9-11]. Breeding for increased grain yield tends to increase starch more than protein, resulting in flour with a lower 
protein percentage, and there seems to be a limit to maximum grain protein content in high yielding varieties [35,12] although there are exceptions [7]. When wheat is grown under cool, well-watered conditions, it is possible to obtain high grain yield together with high protein concentration by supplying nitrogen after anthesis $[10,13,14]$. However, additional nitrogen alters grain amino acid content and there is a negative relationship between protein concentration and the concentration of essential amino acids such as lysine, cysteine and methionine [12].

There is also a trade-off between grain yield and protein content under conditions of drought and/or high temperature, which reduce accumulation of starch more than protein $[10,15]$. This is partly because high temperature reduces transcript levels and enzyme activity of starch synthase $[15,16]$. High protein flours produced under conditions of high temperature were also reported to have increased proportions of glutamine- and proline-rich proteins and reduced proportions of cysteine- and methionine-rich proteins [11]. Understanding the molecular mechanisms that regulate the balance between starch and protein synthesis could aid in efforts to uncouple the inverse relationships between starch and protein synthesis and between desirable amino acid composition versus high protein content.

Grain-fill depends upon import of sugars and amino acids from the leaves and stem. Nutrients are unloaded from the phloem into the endosperm cavity and taken up by endosperm cells in the region of the crease [17]. Carbohydrate supply to the grain is mainly in the form of sucrose [18]. Amino acid supply is mainly as glutamine, alanine, serine and glycine $[19,20]$ and sulfur is imported as sulfate, glutathione and S-methylmethionine [21-23]. Within the endosperm, these molecules are converted into the other sugars, complex carbohydrates, amino acids, nucleic acids, enzymes and structural proteins, lipids, and membranes needed for cell development as well as the abundant starch and storage proteins that will support the embryo upon germination. Molecules synthesized in the endosperm also are transported into the scutellum of the growing embryo [24,25].

Many of the metabolic pathways for synthesis of amino acids, isoprenoids, lipids and other products are located within plastids $[26,27]$, so it is logical that these essential molecules are synthesized within the amyloplasts. At 10 to 12 DPA the amyloplasts are large amorphous organelles. Outer and inner envelopes surround an extensive matrix within which a starch granule gradually enlarges $[28,29]$. Proteomic studies provided lists of proteins found in fractions highly enriched in these amyloplasts, but did not clearly distinguish between true amyloplast proteins and contaminants from the cytoplasm and other organelles [6,30,31]. However, two of the studies [6,31] suggested that amyloplasts are involved in many metabolic functions in addition to starch production. This paper reduces the number of putative amyloplast proteins in [6] from $90 \%$ to $62 \%$ of those detected and then organizes them into proposed metabolic and biosynthetic pathways. The enzymes are arranged into maps that include enzyme and compound names in a single view. The paper summarizes the evidence for each pathway and its role in grain development. Links to the original MS/MS data are provided. The analysis should be useful in eventual on-line maps of wheat metabolic enzymes in the manner of AraCyc [32] or RiceCyc [33]. Unlike AraCyc or RiceCyc it summarizes the pathway evidence from the point of view of a single organelle.

\section{Results and Discussion}

Categorization of proteins in the amyloplast preparation Analysis of the 288 proteins detected in the amyloplast fraction [6] indicated that 177 originated in amyloplasts (62\%) (Tables 1, 2, 3, 4). Also see Additional file 1. Another three proteins of unknown function were equally likely to be from plastid or mitochondrion, and 10 were of unknown function or location. It was determined that the remaining proteins most likely were not amyloplast proteins. The table in Additional file 1 gives the sequence that was the best fit to the tandem MS/MS data for the tryptic peptides from each protein. For the 288 proteins, only 33 best matches were to proteins from the NCBI nonredundant database [34], whereas 255 were contigs from wheat EST databases [35-37]. Although this indicates the excellent coverage of wheat sequences in current EST databases, using these sequences to predict a plastid transit peptide was problematic. Many of the wheat contigs were partial, composed of ESTs from multiple varieties, lacked the coding region for the $\mathrm{N}$-terminal protein sequence, or had other potential problems. It requires considerable analysis to assemble a reliable contig with the best fit for an individual protein, as illustrated in studies of omega gliadins and lipid transfer proteins by Altenbach et al. $[38,39]$. Therefore, the decision was made to use the predicted peptides for a BLAST [40] search of the NCBI nonredundant database to find the most closely related homolog for which a complete protein sequence could be deduced. For the 180 likely amyloplast proteins, 21\% of the closest homologs in the nonredundant database were predicted products of wheat (Triticum aestivum) genes or wheat cDNA clones and $68 \%$ were the predicted products of rice (Oryza sativa) genes. These were analyzed using Target $P$ to predict organellar transit peptides [41]. The analysis does not prove whether the actual wheat protein had a transit peptide, but indicates whether the closest known homolog did. 
Table I: Proteins of carbohydrate metabolism that were detected and proposed to be wheat amyloplast constituents 1

\begin{tabular}{|c|c|}
\hline Carbohydrate metabolism & Plastid Criteria' \\
\hline \multicolumn{2}{|l|}{ Glucose metabolism } \\
\hline I Glucose-6-phosphate isomerase EC 5.3.1.9 & I, 2(ch), 3(ch), 4 \\
\hline 2 Hexokinase EC 2.7.I.I & 2 (ch/cy), 3 (ch/mi), 4 \\
\hline \multicolumn{2}{|l|}{ Glycolysis } \\
\hline 3 Fructose-bisphosphate aldolase EC 4.1.2.13 & I, 2(ch/cy), 3(ch), 4 \\
\hline 4 Glyceraldehyde-3-phosphate dehydrogenase EC 1.2.1.12 & 2(ch/cy), 3(ch), 4 \\
\hline 5 Phosphoenolpyruvate mutase-like EC 5.4.2.9 & 2(ch), 3(ch) \\
\hline 6 Phosphoglycerate dehydrogenase EC I.I.I.95 & I, 2(ch), 3(ch), 4 \\
\hline 7 Phosphoglycerate kinase EC 2.7.2.3 & I, 2(ch/cy), 3(ch), 4 \\
\hline 8 Phosphopyruvate hydratase EC 4.2.I.II & $2(\mathrm{ch} / \mathrm{cy} / \mathrm{mi}), 3(\mathrm{mi} / \mathrm{ch}), 4$ \\
\hline 9 Pyruvate kinase, putative EC 2.7.1.40 & 2(ch/cy), 3(ch), 4 \\
\hline 10 Triosephosphate isomerase EC 5.3.I.I & 2(ch/cy/pl), 3(ch), 4 \\
\hline
\end{tabular}

\section{Pyruvate dehydrogenase complex}

II Dihydrolipoyllysine-residue acetyltransferase EC 2.3.1.12

12 Lipoamide dehydrogenase EC 1.8.1.4

13 Pyruvate dehydrogenase EI alpha subunit EC 1.2.4.1

14 Pyruvate dehydrogenase EI beta subunit EC I.2.4.I 2(ch/pl), 3(ch), 4

$2(\mathrm{ch} / \mathrm{mi} / \mathrm{pl}), 3(\mathrm{ch}), 4$

$2(\mathrm{ch} / \mathrm{mi} / \mathrm{pl}), 3(\mathrm{ch}), 4$

2(ch/mi/pl), 3(ot), 4

\section{Citrate and malate}

I5 Aconitate hydratase, putative EC 4.2.1.3

16 Malic enzyme (NADP-dependent) EC I.I.1.39 2(ch, cy, mi), 3(ch)

2(ch, cy, mi), 3(ch), 4

\section{Starch metabolism}

17 4-alpha-glucanotransferase EC 2.4.I.25

18 Alpha I,4-glucan phosphorylase EC 2.4.I.I

19 Glucose-I-phosphate adenylyltransferase large subunit (ADP-G) EC 2.7.7.27

20 Glucose-I-phosphate adenylyltransferase small subunit EC 2.7.7.27

2 I Glucose-I-phosphate adenylyltransferase, small subunit EC 2.7.7.27

22 NDP-glucose-starch glucosyltransferase (granule bound starch synthase) EC 2.4.I.242

23 I,4-alpha-glucan branching enzyme (starch branching enzyme 2) EC 2.4.I.I8

24 Starch synthase II EC 2.4.1.21
I, 2(am, ch, cy, pl), 3(ot), 4

I, 2(am, ch, cy), 4

I, 2(am, ch, cy), 3(ch), 4

I, 2(am), 3(ch), 4

I, $2(\mathrm{am}, \mathrm{pl}), 4$

I, $2(\mathrm{am}), 3(\mathrm{ch}), 4$

\section{Pentose phosphate cycle}

25 Glucose-6-phosphate dehydrogenase EC I.I.I.49

26 Phosphoribulokinase EC 2.7.1.19

27 Ribose-5-phosphate isomerase EC 5.3.1.6

28 Ribulose 1,5-bisphosphate carboxylase, large subunit EC 4.1.1.39

29 Transaldolase, putative EC 2.2.1.2

30 Transketolase EC 2.2.1.I 2(ch, cy), 3(ch), 4

2(ch), 3(ch), 4

2(ch), 3(ch), 4

I, 2(ch), 3(ot), 4

2(mi, pl), 3(ch), 4

2(ch, cy), 3(ch), 4

\section{I-Carbon metabolism}

3I Formate-tetrahydrofolate ligase EC 6.3.4.3

32 Glycine hydroxymethyltransferase EC 2.1.2.I 2(ch, cy, mi, pl), 3(ch), 4

2(ch, cy, mi, pl), 3(ch), 4

'Criteria: I) Known amyloplast or chloroplast protein in wheat; 2) annotated as amyloplast, plastid or chloroplast protein for other plant species in the BRENDA [100] or NCBI [34] databases, or identified as such in a reference in this paper; 3) Target P [4I] predicts a plastid transit peptide for the protein product of the wheat gene or homolog; 4) other members of the same pathway or protein complex are known plastid proteins. The following abbreviations are used: am, amyloplast; ch, chloroplast; cy, cytoplasm; en, endomembrane; gl, glyoxysome; mi, mitochondria; nu, nucleus; ot, other; pe, peroxisome; pl, plastid; 
Table 2: Proteins of amino acid metabolism that were detected and proposed to be wheat amyloplast contsituents'

\author{
Amino acid synthesis
}

Aromatic amino acids

33 Anthranilate synthase, beta subunit EC 4.1.3.27

34 3-dehydroquinate dehydratase/shikimate dehydrogenase EC 4.2.I.I0/EC I.I.I.25

35 3-dehydroquinate synthase EC 4.2.3.4

36 3-phosphoshikimate I-carboxyvinyltransferase EC 2.5.I.19

37 Phosphoribosylanthranilate isomerase I EC 5.3.I.24

38 Tryptophan synthase alpha chain EC 4.2.1.20

39 Tryptophan synthase beta subunit EC 4.2.1.20

2(ch, cy, pl), 3(ch), 4

2(ch), 3(ch), 4

2(ch), 3(ch), 4

2(ch), 3(ch), 4

2(pl), 3(ch), 4

2(ch), 3(ch), 4

2(ch), 3(ch), 4

\title{
Aspartate, alanine, lysine and threonine
}

40 Aspartate transaminase EC 2.6.1.I

4I Aspartate kinase-homoserine dehydrogenase EC 2.7.2.4/EC I.I.I.3

42 Aspartate-semialdehyde dehydrogenase EC I.2.1.I I

43 Diaminopimelate decarboxylase EC 4.1.1.20

44 Diaminopimelate epimerase-like protein EC 5.I.I.7

45 Dihydrodipicolinate reductase-like EC 1.3.1.26

46 Dihydrodipicolinate synthase I EC 4.2.1.52

47 Threonine synthase EC 4.2.99.2
2 (am, ch, cy), 3(ch), 4 2(ch, pl, cy), 3(ch), 4

2(ch, mi), 3(ch), 4

2(ch), 3(ch), 4

2(ch), 3(ch), 4

2(ch), 3(ch), 4

2(ch), 3(ch), 4

2(ch), 3(ch), 4

\section{Branched chain amino acids}

48 Acetolactate synthase EC 4.1.3.18

49 Branched-chain amino acid aminotransferase EC 2.6.1.42

50 Dihydroxy-acid dehydratase EC 4.2.1.9

5I 3-isopropylmalate dehydratase, large subunit EC 4.2.1.33

52 3-isopropylmalate dehydratase, small subunit EC 4.2.1.33

53 3-isopropylmalate dehydrogenase EC I.I.I.85

54 2-isopropylmalate synthase A EC 2.3.3.13

55 Ketol-acid reductoisomerase EC I.I.I.86 2(ch), 3(ch), 4

2(ch, cy, mi, pl), 3(ch), 4

2(ch, mi), 3(ch), 4

2(ch), 3(ch, mi), 4

2(ch), 3(ch), 4

2(ch), 3(ch, mi), 4

2(ch), 3(ch), 4

2(ch), 3(ch), 4

Cysteine and sulfur metabolism, sulfur assimilation

56 Cystathionine beta-lyase EC 4.4.I.8

57 Cysteine S-conjugate beta-lyase EC 4.4.1.13

58 Cysteine synthase I EC 2.5.1.47

59 Glutamate-cysteine ligase EC 6.3.2.2

60 Phosphoadenylyl-sulfate reductase EC I.8.4.8

6I Sulfate adenylyl transferase EC 2.7.7.4

62 Thiosulfate sulfurtransferase EC 2.8.I.I 2(ch, cy), 3(ch), 4

2(mi), 3(ch), 4

2(ch, cy, mi, pl), 3(ch), 4

2(ch, cy), 3(ch, mi), 4

2(ch), 3(ch), 4

2(ch, cy), 3(ch), 4

2(ch, cy, mi), 3(ch), 4

Glutamine, glutamate and asparagine

$63 \mathrm{~N}$-acetyl-gamma-glutamyl-phosphate reductase EC 1.2.1.38

64 Acetylglutamate kinase-like protein EC 2.7.2.8

65 Acetylornithine aminotransferase EC 2.6.1.11

66 Argininosuccinate lyase EC 4.3.2.1

67 Argininosuccinate synthase EC 6.3.4.5

68 Ferredoxin-dependent glutamate synthase (FD-GOGAT) EC I.4.7.I

69 Ornithine carbamoyltransferase EC 2.1.3.3 2(ch), 3(ch), 4

2(ch), 3(ch), 4

2(ch, mi), 3(ch), 4

2(ch), 3(ch), 4

2(ch), 3(ch, ot), 4

2(ch), 3(ch), 4

2(ch), 3(ch), 4

\section{Histidine}

70 ATP phosphoribosyl transferase EC 2.4.2.17

7I Histidinol dehydrogenase EC I.I.I.23

72 Imidazoleglycerol phosphate synthase hisHF EC not available

73 Phosphoribosyl-ATP diphosphatase EC 3.6.1.31

74 I-(5-phosphoribosyl)-5-((5-phosphoribosylamino) methylideneamino) imidazole-4-carboxamide isomerase EC 5.3.I.I6

2(ch), 3(ch), 4

2(ch), 3(ch), 4

2(ch), 3(ch), 4

2(ch), 3(ch), 4

2(ch, mi), 3(ch, mi), 4

ICriteria: as in Table I. 
Table 3: Proteins involved in synthesis of nucleic acids, porphyrins, isoprenoids, vitamins and fatty acids that were detected and proposed to be wheat amyloplast constituents'.

\begin{tabular}{|c|c|}
\hline Nucleic acid synthesis & \\
\hline \multicolumn{2}{|l|}{ General } \\
\hline 75 Inorganic diphosphatase EC 3.6.I.I & 2(ch, ot), 3(ch), 4 \\
\hline 76 Quinolinate synthase A EC not available & $2(\mathrm{ch}), 3(\mathrm{ch}), 4$ \\
\hline 77 Nucleoside diphosphate kinase EC 2.7.4.6 & 2(ch, cy), 3(ch), 4 \\
\hline
\end{tabular}

\section{Purines}

78 Adenylate kinase A EC 2.7.4.3

79 Adenylosuccinate synthetase EC 6.3.4.4

80 Phosphoribosylaminoimidazolecarboxamide formyltransferase EC 2.1.2.3

8I Phosphoribosylformylglycinamidine cyclo-ligase EC 6.3.3.

82 Phosphoribosylaminoimidazolesuccinocarboxamide synthase EC 6.3.2.6

2(ch, cy), 3(ch), 4

I,2(ch), 3(ch, mi), 4

2(ch, mi, nu), 3(ch), 4

2(ch, cy, mi, pl), 3(ch), 4

\section{Pyrimidines}

83 Aspartate carbamoyltransferase EC 2.1.3.2

84 Carbamoyl phosphate synthetase, large subunit EC 6.3.5.5

85 Carbamoyl phosphate synthase, small subunit, glutamine dependent form EC 6.3.5.5

86 Dihydroorotate dehydrogenase EC I.3.99.1I
I, 2(ch), 3(ch, mi), 4

2(ch, cy), 3(ch), 4

2(ch, cy), 3(ch), 4

2(ch, cy), 3(ch), 4

\section{Porphyrin synthesis}

87 Coproporphyrinogen oxidase EC 1.3.3.3

88 Ferritin (no EC number)

89 Ferrochelatase EC 4.99.1.

90 Glutamate-I-semialdehyde 2, I-aminomutase EC 5.4.3.8

91 Heme oxygenase I EC I.14.99.3

92 Hydroxymethylbilane synthase EC 4.3.1.8

93 Porphobilinogen synthase EC 4.2.1.24

94 Uroporphyrinogen decarboxylase EC 4.I.I.37 2(ch), 3(ch), 4 2(ch), 3(ch, mi), 4 2(ch, mi), 3(ch), 4 2(ch), 3(ch), 4 $3(\mathrm{ch}), 4$ 2(ch), 3(ch), 4 2(ch, cy, pl), 3(ch), 4 2(ch, pl), 3(ch), 4

\section{Isoprenoids}

95 2-C-methyl-D-erythritol 4-phosphate cytidylyltransferase EC 2.7.7.60

96 4-hydroxy-3-methylbut-2-en-I-yl diphosphate synthase EC I.I 17.4.3

97 Isopentenyl diphosphate DELTA DELTA 2 isomerase EC 5.3.3.2

98 Phytoene synthase EC 2.5.1.32

99 Phytoene desaturase EC I.14.99.3? 2(ch, pl), 3(ch), 4

2(ch), 3(ch), 4

2(ch, mi, pe, pl), 3(ch), 4

2(ch, pl), 3(ch), 4

$3(\mathrm{ch}), 4$

\section{Vitamins and cofactors}

100 Pyridoxamine 5'-phosphate oxidase-related domain containing protein EC 1.4.3.5 (related)

101 Riboflavin synthase, alpha chain EC 2.5.1.9

102 Thiamine biosynthesis protein ThiC EC not available

103 Tocopherol cyclase EC not available

104 Tocopherol methyltransferase EC 2.1.I.95 $3(\mathrm{ch}, \mathrm{mi}), 4$

3 (ch), 3(ch), 4

2(ch), 3(ch), 4

2(ch), 3(ch), 4

2(ch), 3(ch), 4

\section{Fatty acid synthesis}

I05 Acetyl-CoA carboxylase EC 6.4.I.2

106 Acyl-[acyl-carrier-protein] desaturase EC I.14.19.2

107 [acyl-carrier-protein] S-malonyltransferase EC 2.3.1.39

108 Beta-ketoacyl-acyl-carrier-protein synthase I EC 2.3.I.4

109 Enoyl-[acyl-carrier-protein] reductase (NADPH, B-specific) EC I.3.1.10

I 10 3-Hydroxydecanoyl-[acyl-carrier-protein] dehydratase EC 4.2.1.60

I I Oleoyl-[acyl-carrier-protein] hydrolase EC 3.1.2.14

I 12 3-Oxoacyl-[acyl-carrier-protein] reductase EC I.I.1.100 2(ch, cy, mi, pl), 3(ch), 4

2(ch, cy), 3(ch), 4

2(ch, pl), 3(ch), 4

2(ch, mi), 3(ch), 4

2(ch), 3(ch), 4

2(ch), 3(ch), 4

2(ch), 3(ot, ch), 4

2(ch), 3(ch), 4

ICriteria: as in Table I. 
The predicted amyloplast proteins were grouped by function, and 112 enzymes were arranged into maps of proposed metabolic and biosynthetic pathways. Protein numbers refer to Tables 1, 2, 3, 4 and Figure 1. Details are in Additional file 2, Figures 2-17. Also see Additional file 3.

In a previous study [42] salt-soluble endosperm proteins were separated from storage proteins by extraction with $\mathrm{KCl}$, and separated from major albumin storage proteins by precipitation with methanol and ammonium acetate. Amyloplast proteins appear to be of low abundance compared to the proteins in the $\mathrm{KCl}$ extract, which may be enriched in abundant cytoplasmic enzymes [6]. For comparison with other studies, those identified as thioredoxin targets [31] or found in the $\mathrm{KCl}$ extract [42] are indicated (See Additional files 1, 2, 3).

\section{Carbohydrate metabolism (Proteins \# I-32)}

Although amyloplasts are known mainly for starch production, this set of 32 enzymes represented only $18 \%$ of the amyloplast proteins that were detected (Table 1). Sucrose is converted to fructose and UDP-glucose in the cytoplasm by sucrose synthase and then converted to glucose 1-P and glucose 6-P prior to uptake into plastids $[17,26,43,44]$. Plastids also take up carbohydrate precursors in the form of triose phosphate, glucose, pentose phosphates, other hexose phosphates, and ADP-glucose [27]. Glucose-6-P and ADP-glucose are the primary source of carbohydrate for wheat amyloplasts, however, and uptake of triose phosphates is less significant for cereal grain amyloplasts than for other types of plastid $[27,44]$. In addition to enzymes required for starch biosynthesis, most enzymes of glucose metabolism, glycolysis and the pentose phosphate pathway and two of 1-C metabolism were detected.

\section{Glucose Metabolism (Proteins 1-2)}

Proteins \#1 and \#2 are enzymes essential to glucose metabolism. Hexokinase (\#2) is the entry point for glucose into sugar and starch metabolism. It is reported have an isoform in the chloroplast outer envelope [45], but its role in import or export of glucose-6-phosphate is uncertain. The homolog related to the wheat protein had a low Target P score of 0.39 for plastid. Glucose-6-phosphate isomerase (\#1) is at the branch point between starch production, glycolysis, and the pentose phosphate pathway. A plastidic isoform was detected. Two enzymes that convert fructose 6-phosphate to fructose 1,6-phosphate were not detected. Both 6-phosphofructokinase [2.7.1.105] and fructose bisphosphatase [3.1.3.11] have plastid and cytosolic isoforms [43,46]. Fructose bisphosphatase was reported to be missing from endosperm amyloplasts, in agreement with the lack of import of triose phosphates [46]. The other, 6-phosphofructo kinase, was previously identified in the KCl-extract, perhaps as an abundant cytoplasmic form. Either the conversion from fructose 6-phosphate to fructose 1,6-phosphate takes place in the cytoplasm, or the amyloplast enzyme exists but was not detected.

\section{Glycolysis (Proteins \#3-10)}

Seven enzymes of glycolysis were detected along with an enzyme that phosphorylates phosphoenolpyruvate. All seven were predicted to be plastid located. As starch accumulates in the endosperm, $\mathrm{O}_{2}$ levels decrease. Therefore, it was suggested that glycolysis is a more significant source of energy in maize endosperm than is mitochondrial oxidation and the TCA cycle, which require $\mathrm{O}_{2}$ [47]. Glycolysis might be particularly important in the wheat endosperm, which becomes densely packed with protein as well as starch. Fructose-bisphosphate aldolase (\#3) is essential for generating triose sugars. Phosphoglycerate dehydrogenase (\#6) and phosphoglycerate kinase (\#7) are key to ATP and NADH production. Although phosphoglycerate mutase (\#184) was detected, the protein appeared to be the cytoplasmic isoform, based on the Target-P prediction for the most closely related rice gene. It is identified as a plastid or cytosolic enzyme in other plants. If the wheat protein \#184 is actually plastidic, then all of the proteins in the pathway from fructose 1,6-phosphate to pyruvate were detected. Lactoyl glutathione lyase (\#185) was also detected but predicted to be of cytoplasmic origin. Mechin et al. [47] stress the importance of cytoplasmic pyruvate orthophosphate dikinase [EC 2.7.9.1] in maize endosperm. That enzyme was not found in the amyloplast fraction but was detected in the $\mathrm{KCl}$ extract. Phosphoenolpyruvate mutase (\#5) is an enzyme involved in resistance to herbicides.

\section{Pyruvate metabolism (Proteins \#/ I-14)}

Pyruvate is the starting point for synthesis of alanine and aspartate, branched chain amino acids, isoprenoids, carotenoids and other vitamins, and fatty acids. Proteins \#1114 are components of pyruvate dehydrogenase, the entryway to production of acetyl Co-A for fatty acid biosynthesis [48]. Dihydrolipoyllysine-residue acetyltransferase (\#11), lipoamide dehydrogenase (\#12) and the pyruvate dehydrogenase E1 alpha (\#13) and E1 beta (\#14) subunits all have plastidic and mitochondrial isoforms in plants. Target-P predictions for the protein products of 3 of the 4 homologous rice genes indicated a plastid target sequence but the prediction for the pyruvate dehydrogenase E1 beta subunit was "other".

\section{Citrate and Malate (Proteins \#/5-16)}

Two proteins were involved in metabolism of citrate and malate. Plants have isoforms of malic enzyme in cytosol, mitochondria and plastids [49]. The malic enzyme (\#16) detected was similar to a rice gene product that was anno- 
Table 4: Proteins involved in redox systems, photosystems, signalling, transport, protein synthesis, assembly and turnover, plastid division, or unknown functions that were detected and proposed to be wheat amyloplast constituents'.

\section{Redox systems}

\section{Ferredoxin-thioredoxin system}

II 3 Ferredoxin III (no EC)

I I4 Ferredoxin-NADP+ reductase EC I.18.1.2 - non-green isoform

II 5 Ferredoxin-thioredoxin reductase, variable subunit EC not available 2(ch), 3(ch), 4

$2(\mathrm{ch}, \mathrm{pl}), 3(\mathrm{ch}), 4$

2 (ch), $3(\mathrm{ch}), 4$

\section{Free radical scavenger system}

$\begin{array}{lr}\text { II6 Ascorbate peroxidase EC I.II.I.II } & 2(\mathrm{ch}, \mathrm{cy}), 3(\mathrm{ch}), 4 \\ \text { II7 Cu/Zn superoxide dismutase EC I.I5.I.I } & 2(\mathrm{ch}, \mathrm{cy}, \mathrm{mi}), 3(\mathrm{ch}), 4 \\ \text { II8 Glutaredoxin EC I.20.4.I } & 2(\mathrm{ch}), 3(\mathrm{ch}), 4 \\ \text { II } 9 \text { Monodehydroascorbate reductase EC I.6.5.4 } & 2(\mathrm{ch}, \mathrm{cy}, \mathrm{mi}), 3(\mathrm{ch}), 4 \\ \text { I } 2 \text { Peroxiredoxin EC I.II.I.I5 } & 2(\mathrm{ch}), 3(\mathrm{ot}), 4 \\ \text { I2I Peroxiredoxin (Type 2) EC I.II.I.I5 } & 2(\mathrm{ch}), 3(\mathrm{ch}), 4\end{array}$

\section{Photosystem I and II thylakoid proteins}

I22 ATP synthase alpha chain (encoded by chloroplast DNA) EC 3.6.3.14

123 Apocytochrome f precursor (encoded by chloroplast DNA) EC not available

I 24 Chlorophyll a/b binding protein of photosystem II EC not available

I 25 Chlorophyll a/b binding protein of photosystem II EC not available

$12623 \mathrm{kDa}$ oxygen evolving protein of photosystem II EC not available

$12733 \mathrm{kDa}$ oxygen evolving protein of photosystem II EC not available

128 Oxygen-evolving enhancer protein $2 \mathrm{EC}$ not available

129 Photosystem I reaction center subunit II EC not available

\author{
2(ch), 3(ot), 4 \\ 2(ch), 3(ot) but known plastid protein) \\ 2(ch), 3(ch), 4 \\ 2(ch), 3(ch), 4 \\ 2(ch), 3(ch), 4 \\ 2(ch), 3(ch), 4 \\ 2(ch), 3(ch), 4 \\ 2(ch), 3(ch), 4
}

\section{Signaling}

I 30 Inositol phosphate phosphatase EC 3.1.3.25

2(ch), 3(ch), 4

|3| Inositol monophosphatase family protein

\section{Substrate transport}

I32 ABC-type transporter, ATPase component, EC 3.6.3.*

I 33 ABC-type transporter, putative EC 3.6.3.*

134 ADP-glucose transporter

I 35 Amino acid selective channel protein

2(ch), 3(ch), 4

2(ch), 3(ch), 4

2(ch, mi), 3(ch, ot) 4

2(ch),3(ot), 4

Protein synthesis, import, assembly and turnover

\section{Ribosomal Proteins}

$\begin{array}{lr}\text { I } 3629 \text { kDa ribonucleoprotein A } & 2(\mathrm{ch}), 3(\mathrm{ch}), 4 \\ \text { I } 3740 \text { S ribosomal protein S20 } & 2(\mathrm{ch}), 3(\mathrm{ch}, \text { ot), } 4 \\ \text { I } 38 \text { Hypothetical protein OSJNBa007IKI8.7 - unk, possible chloroplast ribosomal 52 } & 2(\mathrm{ch}), 3(\mathrm{ch}, \mathrm{mi}), 4 \\ \text { I } 39 \text { Cp3 IBHv (3I kDa ribonucleoprotein, chloroplast) } & 2(\mathrm{ch}), 3(\mathrm{ch}), 4 \\ \text { I } 40 \text { Ribosome recycling factor } & 2(\mathrm{ch}), 3(\mathrm{ch}), 4 \\ \text { I4I Translational elongation factor Tu } & 2(\mathrm{ch}), 3(\mathrm{ch}), 4 \\ \text { I } 42 \text { Translational inhibitor protein, putative } & 2(\mathrm{ch}), 3(\mathrm{ch}), 4\end{array}$

Protein import

$\begin{array}{lr}\text { 143 Translocon Tic40-like protein } & \text { 2(ch), 3(ch), } 4 \\ \text { 144 Translocon Tic40 } & 2(\mathrm{ch}), 3(\mathrm{ot}), 4 \\ \text { 145 Translocon Ticl10 } & 2(\mathrm{ch}), 3(\mathrm{ot}), 4 \\ \text { I } 46 \text { Translocon Toc34-I } & 2(\mathrm{ch}), 3(\mathrm{ot}), 4 \\ \text { 147 Translocon Toc75 } & 2(\mathrm{ch}), 3(\mathrm{ch}), 4 \\ \text { 148 Translocon Toc75 } & 2(\mathrm{ch}), 3(\mathrm{ch}), 4\end{array}$


Table 4: Proteins involved in redox systems, photosystems, signalling, transport, protein synthesis, assembly and turnover, plastid division, or unknown functions that were detected and proposed to be wheat amyloplast constituents'. (Continued)

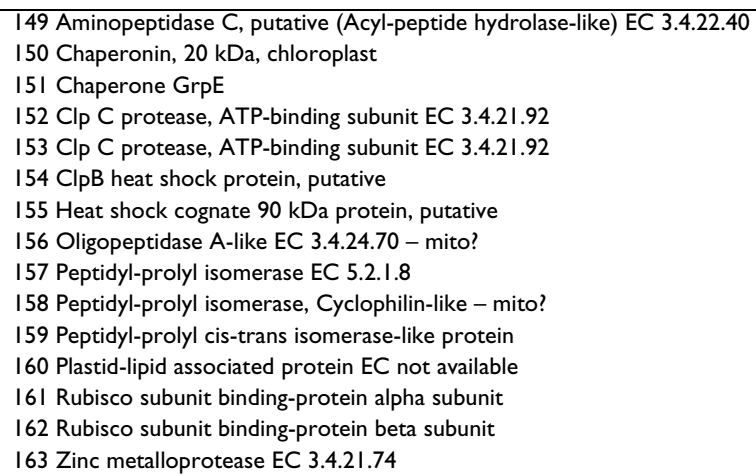

\section{Plastid division}

$\begin{array}{lr}164 \text { FtsZ protein } & 2(\mathrm{ch}), 3(\mathrm{ch}), 4 \\ 165 \text { Plastid division protein [Arc6] } & 2(\mathrm{ch}), 3(\mathrm{ch}), 4\end{array}$

Function is unknown or not verified, but probably located in plastid

I66 Coenzyme F420 hydrogenase-like EC 1.12.99.1

167 Cytochrome b5 domain containing protein

168 Isoflavone reductase related protein EC 1.3.1.45 related

169 Hypothetical protein At Ig26160 - putative metal-dependent phosphohydrolase; biological function unknown

170 Hypothetical protein At2g43940

17I Hypothetical protein At5g08540

172 Hypothetical protein F24D7.19

173 Hypothetical protein OSJNBa0038O10.22

174 Hypothetical protein OSJNBa0054LI4.15, DUF573 family protein of unknown function

175 Hypothetical protein OSJNBa0095E20.4 - CBS domain containing protein; predicted transcriptional regulator. CBS domains are found in otherwise unrelated proteins and enzymes however

176 Hypothetical protein Os06g02 17700 - function unknown

177 Hypothetical protein Os08g0254900 - Fiber protein FB4

178 Hypothetical protein Os08g0254900 - Fiber protein FB4 same gene as above but different peptides and different 2DE spot
2(pl), 3(ch)
2(ch), 3(ch)
$2(\mathrm{ch}), 3(\mathrm{ch})$
2(pl), 3(ch)
2(ch), 3(ch)
2(pl), 3(ch)
2(ch), 3(ch, mi)
2(ch), 3(ch)
2(unk),3(ch)
2(unk), 3(ch)
2(unk), 3(ch)
2(ch), 3(ch)
2(ch), 3(ch)

Function is unknown or not verified, but may be located in plastid and/or mitochondrion

$\begin{array}{ll}\text { I80 Hypothetical protein At3g55760 } & 3(\mathrm{ch}, \mathrm{mi}) \\ \text { I8I Hypothetical protein P0450E05.20 } & 3(\mathrm{ch}, \mathrm{mi}) \\ \text { I82 Glycine-rich RNA-binding protein 2, putative } & 2(\mathrm{mi}), 3(\mathrm{ch})\end{array}$

Probably non-plastid but mentioned in paper

183 Phosphoglucomutase EC 5.4.2.2

I84 Phosphoglycerate mutase EC 5.4.2.I

I 85 Lactoylglutathione lyase EC 4.4.1.5

I86 6-phosphogluconate dehydrogenase EC I.I.I.44

\section{2(ch, cy), 3(ot),}

2(pl, cy), 3(ot)

2(cy, mi), 3(ot)

2(am, ch, cy, pl), 3(sp)

'Criteria: as in Table I.

tated as a plastid protein and predicted to have a plastid transit peptide. Malic enzyme (\#16) provides NADPH and pyruvate for lipid biosynthesis. The citrate cycle is primarily in mitochondria, but aconitate hydratase or a related protein (\#15) had a predicted plastid transit peptide.

Starch biosynthesis (Proteins \# I 7-24)

Five enzymes required for starch biosynthesis were detected. The essential substrate for starch formation is ADP-glucose, produced from glucose 1-phosphate and
ATP in the cytoplasm and plastid of cereal endosperm cells. Wheat endosperm has cytoplasmic and amyloplast forms of glucose-1-phosphate adenylyltransferase $[17,50]$. Amyloplast forms of the large (\#19) and small subunit (\#20-21) were detected. The capacity for cytoplasmic synthesis of ADP-glucose may increase during grain development [26]. A subunit of the putative ADPglucose transporter (\#134) was detected (see below) suggesting that even at 10 DPA the amyloplasts also import ADP-glucose from the cytoplasm. Phosphoglucomutase 


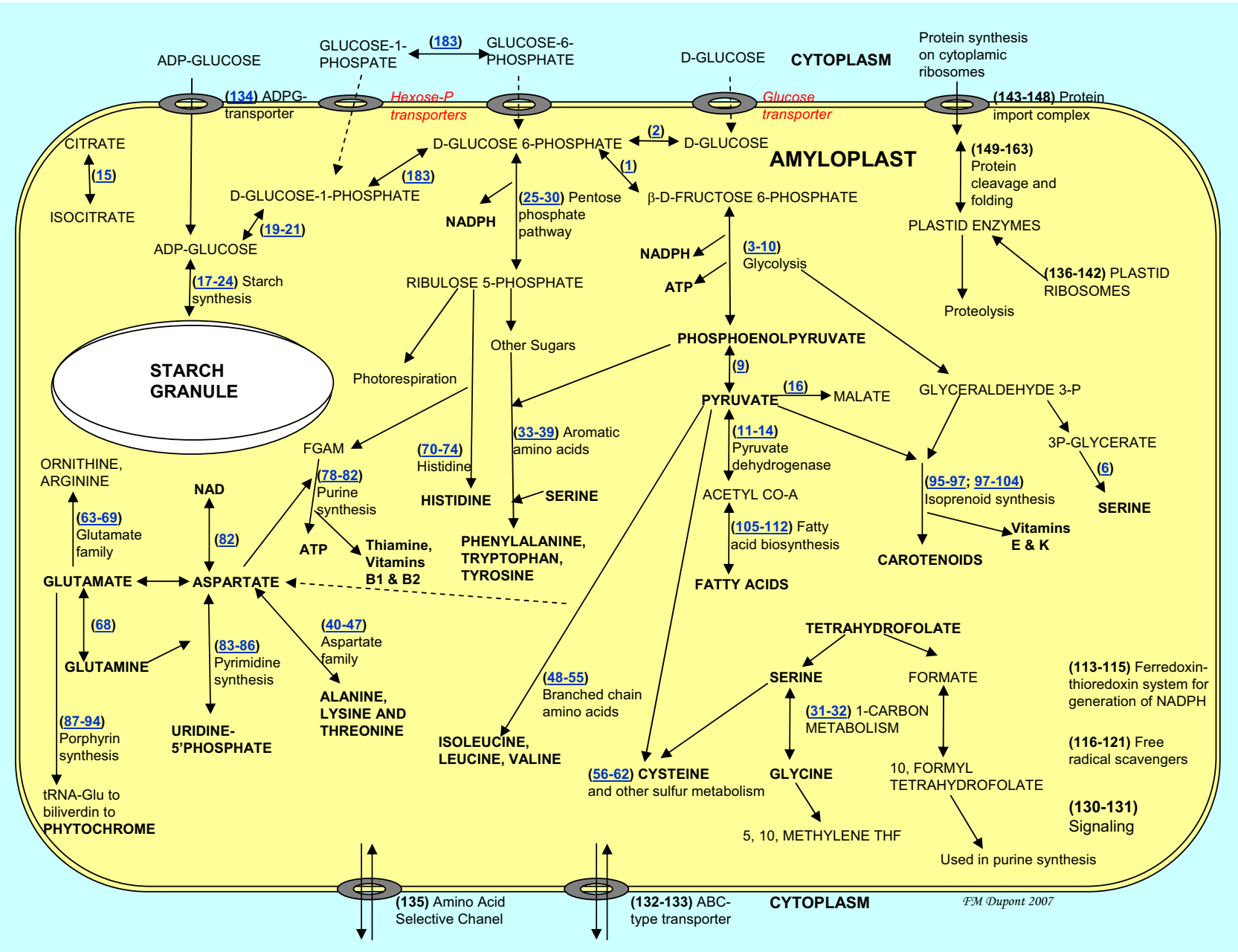

Figure I

Summary of metabolic pathways predicted from a proteomic analysis of IO DPA amyloplasts from the wheat endosperm. The numbers correspond to the proteins listed in Table I. Red font indicates that the protein was not detected in the amyloplast preparation. FGAM is formylglycinamidine-ribonucleotide.

(\#183), which converts glucose 6-phosphate to glucose 1phosphate, appeared to be the cytosolic isoform, based on a Target P prediction of "other". Enzymes for starch biosynthesis include NDP-glucose-starch glucosyltransferase (granule-bound starch synthase) (\#22), 1,4-alpha-glucan branching enzyme 2 (\#23), starch synthase II (\#24), and 4-alpha-glucanotransferase (disproportionating enzyme) (\#17). Basically the above enzymes transfer the glucose residues from ADP-glucose onto simple and branched glucose chains of amylose and amylopectin in a series of steps that includes trimming the chains so that layers of amylopectin interspersed with amylose are deposited onto the growing starch granule (reviewed in [51]). The role of alpha 1,4-glucan phosphorylase (\#18) is uncertain. The enzymes for starch biosynthesis were detected in the membrane fraction, which included starch granules [6].
Not all enzymes of starch biosynthesis were detected, however, including starch synthase I, III or IV, starch branching enzyme 1, debranching enzymes, and alphaand beta-amylases required for starch degradation.

\section{Pentose phosphate pathway (Proteins \#25-30)}

Six proteins were detected in the pentose phosphate pathway that convert glucose 6-phosphate to ribulose 5-phosphate and then to other three-, five- and seven-carbon sugars. Nonoxidative reactions of the pentose phosphate pathway are confined to plastids, and plastids are the only source of ribose 5-phosphate for nucleic acid synthesis [26]. However, isoforms of glucose-6-phosphate dehydrogenase and 6-phosphogluconate dehydrogenase are found in cytosol and plastid. The plastidic form of glucose-6-phosphate dehydrogenase (\#25) was detected, but 
the 6-phosphogluconate dehydrogenase (\#186) was predicted to be the cytosolic form. The other enzymes were predicted to be plastidic. Although ribulose 1,5-bisphosphate carboxylase (\#28) is mainly associated with $\mathrm{CO}_{2}$ fixation in chloroplasts, there are indications that it also plays a role in non-photosynthetic tissue $[52,53]$. Two additional enzymes of the pentose phosphate pathway, gluconolactonase [EC 3.1.1.17] and ribulose 5-phosphate 3-epimerase [EC 5.1.3.1] were not detected.

Folate I carbon (IC) metabolism (Proteins \#3 I-32)

Two enzymes crucial to $1 \mathrm{C}$ metabolism were identified. In plants, there are $1 \mathrm{C}$ pathways in plastids, mitochondria and cytosol. The 1 formate-tetrahydrofolate ligase (\#31) and glycine hydroxymethyltransferase (\#32) proteins that were detected were predicted to be the plastid isoforms. Transfer of methyl groups by these enzymes is essential for interconversion of glycine and serine and synthesis of purine nucleotides [54]. Other members of the pathway were not detected. Synthesis of tetrahydrofolate in plants requires mitochondrial and cytoplasmic enzymes [55] so it is likely that tetrahydrofolate itself is imported into the plastid, and possibly imported into the grain from the leaves, although little is known about source/sink relations for this compound.

\section{Amino acid synthesis (Proteins \#33-74)}

The 42 proteins involved in amino acid synthesis represent $24 \%$ of the proteins identified as amyloplast constituents (Table 2). Almost all steps of amino acid biosynthesis occur within plastids [27] with the principal exception of methionine synthesis and some steps in synthesis of cysteine and proline. The high demand for energy and reducing power for amino acid biosynthesis is met by carbohydrate oxidation, including the oxidative pentose phosphate pathway. Enzymes were present for each of the plastidic pathways for biosynthesis of the amino acids, except that no enzymes involved in the metabolism of proline or asparagine were detected.

Although amino acids are imported from leaves, the compositions of the grain phloem sieve tube sap and endosperm cavity differ significantly from that of the endosperm, indicating that synthesis of many amino acids takes place within the endosperm. Seive tube sap contained more glutamine (64\%) and serine than any other amino acid [19]. The most abundant amino acids in the endosperm cavity were glutamine $(\sim 43 \%)$, alanine ( $20 \%)$, and serine ( 13\%) [19-21]. Asparagine [20] and glycine [21] were also reported to be abundant. Cysteine and methionine were virtually absent from the sieve tube sap and concentrations of proline and aromatic amino acids were low. Synthesis of proline, leucine, tyrosine, cysteine, and methionine take place largely within the endosperm. Highest rates of net synthesis in the endosperm were reported for proline, leucine, tyrosine, valine, isoleucine and phenylalanine, with an estimate of $170,89,42,48,44$ and 44 nmole day-1, in that order [20].

\section{Aromatic amino acids (Proteins \#33-39)}

All enzymes required for synthesis of the aromatic amino acids tryptophan, tyrosine and phenylalanine from phosphoenol pyruvate and erythrose 4-phosphate are located in the plastid [56]. Six of these enzymes were detected. Three were on the shikimate pathway from phosphoenolpyruvate and erythrosose 4-phosphate to chorismate (\#34-36), including the dual-function 3-dehydroquinate dehydratase/shikimate:NADP dehydrogenase (\#34) and three on the pathway from chorismate to tryptophan (\#33,37-39). The Arabidopsis or rice homologs for these enzymes encode proteins with predicted plastid transit peptides. Four additional enzymes required for synthesis of phenylalanine and tyrosine from chorismate were not detected, even though tyrosine and phenylalanine ranked third and fourth for net synthesis during grain-fill [20]. The shikimate pathway is also the starting point for synthesis of other compounds that contain aromatic rings, many of which are derived from phenylalanine [56].

\section{Aspartate family of amino acids (Proteins \#40-47)}

Eight enzymes in the pathways for biosynthesis of alanine, aspartate, lysine and threonine were detected. Plastid transit peptides were predicted for the homologs from Arabidopsis and rice and for dihydropicolinate synthase (\#46), the one protein in this pathway for which a wheat gene has been described. In some grains, asparagine is one of the primary amino acids imported into the endosperm, where it serves as a source of aspartate, an essential intermediate in the synthesis of other amino acids [57]. However, asparaginase [EC 3.5.1.1] was not detected in this study or in [42]. Aspartate is the precursor of threonine and lysine, and is also involved in transamination reactions for production or deamidation of glutamate and glutamine [57]. Six of seven enzymes in the pathway from aspartate to lysine were detected (\#41-46), and an additional enzyme in the pathway from aspartate to threonine (\#47). Also detected was aspartate transaminase (\#40), which catalyzes formation of glutamate from aspartate, and is an essential enzyme in synthesis of alanine. Alanine transaminase [EC 2.6.1.2] was not identified. It was present in the $\mathrm{KCl}$-extract and may be a cytosolic enzyme. Alanine was reported to be present at a higher concentration in the endosperm cavity than in the phloem exudate, suggesting that additional alanine is produced as amino acids are transported into the grain [19].

\section{Branched chain family of amino acids (Proteins \#48-55)}

All seven enzymes in the pathway for biosynthesis of isoleucine, leucine and valine were present, and thiamine is a cofactor in this pathway. Although there are two sepa- 
rate pathways, one from pyruvate and hydroxyl-ethyl-2thiamine diphosphate to valine and leucine, and one from hydroxyl-ethyl-2-thiamine diphosphate and oxobutyrate to isoleucine, four of the enzymes are found in both pathways (\#48-50,55). Five proteins were predicted to have plastid target peptide sequences. The prediction for the other two, the large subunit of 3-isopropylmalate dehydratase (\#51) and 3-isopropylmalate dehydrogenase (\#53), was ambiguous for plastid or mitochondrion.

Cysteine, methionine and other sulfur compounds (Proteins \#56-62) Import of sulfur into the grain is largely in the form of glutathione, S-methyl-methionine and sulfate $[21,22]$. Synthesis of cysteine and methionine takes place in the endosperm and may limit the synthesis of sulfur-rich endosperm proteins, thus affecting flour quality and nutritional value. Seven enzymes involved in biosynthesis and metabolism of cysteine and other S-compounds were detected. Enzymes for cysteine synthesis in plants are located in plastids, mitochondria, and cytoplasm [58]. Two were detected in the amyloplast preparation and predicted to be plastid located. Sulfate adenylyl transferase (\#61) adds a sulfate to ATP to create adenylyl-sulfate, and cysteine synthase (\#58) is a multienzyme complex that converts acetyl serine and hydrogen sulfide into cysteine. Adenylyl sulfate also is the sulfur donor for synthesis of the sulfo-lipid sulfoquinovosyldiacylglyceride. Although the enzyme 5'-adenylylsulfate reductase [EC 1.8.4.9] is a key enzyme in conversion of sulfate to cysteine, and is known to be a plastid enzyme [58] it was not detected, nor was the other enzyme required for reduction of sulfate, ferredoxin-dependent sulfite reductase [EC 1.8.7.1]. Serine acetyl transferase [EC 2.3.1.30] was not detected. It supplies the carbon backbone for cysteine and is located in plastids, cytoplasm and mitochondrion, but is not abundant and may be rate-limiting for cysteine production [58]. One of three enzymes needed for production of glutathione was detected, glutamate-cysteine ligase (\#59). It joins cysteine to glutamate to produce gamma-glutamyl cysteine and had a target prediction of plastid or mitochondrion. Since sulfur is imported as glutathione, one pathway for cysteine production could be from glutathione to glutamate plus cysteine. Anderson and Fitzgerald [21] suggested this is energetically unfavorable, however, and that there may be an alternate route from glutathione to cysteine.

Cystathionine gamma-synthase [EC 2.5.1.48] is a plastidlocated enzyme responsible for synthesis of cystathionine, on the pathway to methionine synthesis [58,59], but it was not detected. However, cystathionine beta lyase (\#56) was detected. It is responsible for breakdown of cystathionine to pyruvate and homocysteine, a key intermediate in methionine production that is produced only in plastids. Other enzymes of cysteine metabolism that were detected included phosphoadenylyl sulfate reductase (\#60) which transfers sulfate to thioredoxin, and cysteine conjugate beta-lyase (\#57) which is required for synthesis of other sulfated compounds. Thiosulfate sulfur transferase (\#62) is involved in breakdown of cysteine to pyruvate and sulfate. Methionine synthase and S-adenosyl methionine synthase are primarily cytoplasmic and were detected in the $\mathrm{KCl}$-extract but not in the amyloplast preparation.

\section{Glycine and serine (Proteins \#6,32)}

Serine is an abundant import but may also be synthesized in the amyloplast. Phosphoglycerate dehydrogenase (\#6), an enzyme in the pathway from glycolysis to serine [60], was the only member of this pathway detected in the amyloplast preparation. The main route for synthesis of glycine is reported to be from serine by the action of glycine hydroxylmethyltransferase (\#32) [61], which was detected. Net synthesis of glycine in the endosperm is unnecessary, however [20].

\section{Glutamate family (Proteins \#63-69)}

Seven of nine enzymes in the pathway for biosynthesis of arginine, glutamate, and glutamine were present and predicted to have plastid transit peptides, even though glutamine is one of the major amino acids imported into the endosperm [19] and glutamine uptake was essential for protein production in maize endosperm [62]. Two essential enzymes for interconversion of glutamate, glutamine and aspartate were detected. Ferredoxindependent glutamate synthase (\#68) is essential for interconversion of glutamate and glutamine, and aspartate transaminase (\#40) for interconversion of glutamine and aspartate. The three enzymes in the pathway from glutamate to proline were not detected, even though proline is one of the most abundant endosperm amino acids and little proline is imported. Enzymes of the pathway from ornithine to proline also were not detected. One of these, pyrroline-5-carboxylate reductase [EC 1.5.1.2] is reported to be located both in plastids and in the cytoplasm but these enzymes are reported to be difficult to detect in plants [63].

\section{Histidine (Proteins \#70-74)}

Four of five enzymes in the joint pathway for synthesis of histidine and purine nucleotides were detected (\#70, 7274 ), along with one of the three enzymes unique to histidine synthesis (\#71). Imidazole glycerol phosphate synthase (\#72) is at the branch point between histidine and purines. The homologs encoded proteins with predicted plastid target peptides, except that \#74 had a prediction of plastid or mitochondrion.

\section{Nucleic acid biosynthesis (Proteins \#75-86)}

Twelve enzymes required for nucleic acid biosynthesis were detected (Table 3). Nucleic acids synthesized in the 
plastid may subsequently be used in the nucleus for synthesis of DNA and RNA. However, adenine nucleotides are also required for energy metabolism and NAD for transfer of reducing power in the plastid. Uridine is used for cytoplasmic processes requiring UTP, such as glycosylation of sugars. Five of eight enzymes required for purine synthesis were detected (\#78-82) and three of six required for pyrimidine synthesis (\#83-86). There is limited information on the cellular location of enzymes of purine and pyrimidine synthesis in plants. Nucleic acids are produced through de novo and salvage pathway and the enzymes are unstable and not abundant [64]. One report indicates that purine synthesis occurs in plastids and mitochondria [65]. Quinolinate synthase (\#76) is one of four required for synthesis of NAD (\#76) and was recently described in a study that indicates that the enzymes for synthesis of NAD are located in plastids but probably not abundant [66]. In this study, plastid transit peptides were predicted for 10 of the 12 protein detected, and plastid or mitochondrial transit peptides were predicted for the other two. This suggests that the amyloplast is a center for nucleic acid synthesis.

\section{Porphyrins (Proteins \#87-94)}

Seven of ten enzymes in the pathway from glutamyl tRNA to biliverdin were detected (\#87,89-94), as well as ferritin (\#88), an iron donor (Table 3). Glutamyl tRNA is the cofactor in the initial conversion of glutamate to aminolevulinate at the start of the pathway for biliverdin biosynthesis [67]. In chloroplasts this pathway is regulated by light and cytokinin [68]. Biliverdin becomes the bilin chromophore that is an essential component of phytochrome. Plastid transit peptides were predicted for all seven enzymes, while there was a prediction of plastid or mitochondrion for the transit peptide of ferritin (\#88).

\section{Isoprenoids, carotenoids and vitamin E (Proteins \#95-99, 103-104)}

Five of 12 enzymes in the isoprenoid pathway from pyruvate and glyceraldehyde 3-phosphate to carotene were detected, and plastid transit peptides were predicted for the rice homologs of all five (Table 3 ). The plastid is the site of the non-mevalonate pathway to isopentyl diphosphate and dimethylallyl diphosphate [69] and two of the seven enzymes in that pathway were detected $(\# 95,96)$ as well as isopentenyl diphosphate isomerase (\#97) which interconverts the two essential isoprenoid intermediates. Two essential enzymes for synthesis of geranylgeranyl diphosphate were not detected, but enzymes on the pathways from geranylgeranyl diphosphate to the carotenoids (\#98-99) and vitamin $\mathrm{E}$ were detected (\#103-104) $[70,71]$.

\section{Other vitamins and cofactors (Proteins \# 100-102)}

Three enzymes involved in vitamin B metabolism were detected (Table 3). Pyridoxamine 5'-phosphate is involved in metabolism of vitamin B6, although the exact function of the "pyridoxamine 5-phosphate oxidaserelated domain containing protein" (\#100) is not known. Two B vitamins are produced from metabolites generated by the pathways for biosynthesis of nucleic acids. Riboflavin synthase (\#101) is a key enzyme in the synthesis of riboflavin (vitamin B2) [72]. Thiamine biosynthesis protein (\#102) is an essential enzyme in the synthesis of thiamine (vitamin B1) which is needed for branched chain amino acid synthesis [73].

\section{Fatty acid biosynthesis (Proteins \# I 05-I I 2)}

The complete set of enzymes required for fatty acid biosynthesis was detected (Table 3). Fatty acids are synthesized only in plastids [27], by successive addition of 2carbon units. This requires ATP and reducing equivalents. Plastids import acetate from the cytoplasm, or use other carbon sources, depending on the plant. Pyruvate dehydrogenase (\#11-14) produces acetyl-Co that is converted into malonyl-CoA by acetyl CoA carboxylase (\#105) and incorporated into fatty acids through the fatty acid cycle by repetition of the reactions catalyzed by enzymes numbered \#107-110 and \#112. The first molecule of acetyl CoA is attached to the acyl-carrier protein, and subsequent molecules of malonyl CoA are added to form the fatty acid in two-carbon steps. The acyl-carrier protein was not detected. Subsequently, oleoyl-(acyl-carrier-protein) hydrolase (\#111) catalyzes release of the fatty acid from the acyl-carrier-protein complex. An additional enzyme that was detected is oleoyl-(acyl-carrier-protein) desaturase (\#106) which is essential for formation of unsaturated fatty acids. Plastid transit peptides were predicted with two exceptions. The Target-P program predicted a mitochondrial transit peptide for the rice gene for acyl[acyl-carrier-protein] desaturase (\#106), and the wheat gene oleoyl-[acyl-carrier protein] hydrolase (\#111) was missing the sequence for the N-terminus. A similar Arabidopsis gene for oleoyl-[acyl-carrier protein] hydrolase did have a predicted plastid transit peptide.

\section{Red-Ox systems (Proteins \# I I 3-I 2 I)}

Nine enzymes were detected that play roles in transfer of reducing equivalents, regulation of protein function through alteration of redox state, and protection from free radicals (Table 4 ).

Ferredoxin-thioredoxin system (Proteins \#/ I3-I/5)

Three proteins required for reduction and oxidation of thioredoxin were detected. All three are known to be located in plastids and had predicted plastid target sequences. The isoform of ferredoxin NADPH reductase (\#114) from non-green plastids uses NADPH to reduce 
ferredoxin, whereas the chloroplast isoform transfers electrons from ferredoxin to generate NADPH [74]. The isoforms operate at a different redox potentials. The nearest homolog to \#114 was a rice protein annotated as the "root isozyme", as were related proteins from maize and Arabidopsis, indicating that \#114 is the isozyme found in nongreen tissue. In amyloplasts NADPH would be generated by glycolysis and the pentose-phosphate pathway. Reduced ferredoxin would then provide reducing power for reduction of sulfite to sulfide in the synthesis of cysteine and for reduction of thioredoxin by ferredoxinthioredoxin reductase (\#115). Thioredoxin was detected in the amyloplast preparation using antibodies against thioredoxin $\mathrm{m}$ and reduced thioredoxin was proposed to modulate the activity of a number of amyloplast enzymes by transfer of reducing equivalents [31]. Candidates for enzymes regulated by thioredoxin are indicated in the pathways linked to Figure 1 and Additional file 1. Many are at pathway branch points or are enzymes involved in generation of ATP or reducing power.

Free-radical scavenger system (Proteins \# I |6-12I)

Six enzymes involved in protection against free radicals were detected (\#116-121). All six are known chloroplast proteins and five were predicted to have plastid transit peptides. Superoxide dismutase (\#117) converts oxygen radicals to peroxide. Subsequently, ascorbate peroxidase (\#116) removes peroxide and generates monodehydrodoascorbate, which is then reduced by monodehydroascorbate reductase (\#119) [75,76]. Peroxiredoxins (\#120,121) catalyze conversion of peroxide to water by transferring reducing equivalents from thioredoxin or glutaredoxin (\#118) to peroxide [75]. Although the presence of a chloroplast glutaredoxin is disputed [77], the Arabidopsis homolog with a good match to the wheat peptide sequences was predicted to have a plastid transit peptide.

\section{Photosystem I and II thylakoid proteins (Proteins \# I22- 129)}

Eight proteins were thylakoid proteins associated with photosystem I and II (Table 4). The three proteins of the oxygen-evolving complex of photosystem II are extrinsic thylakoid proteins found in the thylakoid lumen (\#126128). The ATP synthase subunit (\#122) and apocytochrome $f(\# 123)$ are two of only three proteins in this study that are encoded on the plastid chromosome [7880]. The six nuclear-encoded proteins were all predicted to have plastid transit peptides, whereas the plastidencoded proteins had predictions of "other". The thylakoid proteins could indicate contamination with chloroplasts from the green tissue around the endosperm. However, the amyloplast preparation was white, not green, and it is possible that these are actual amyloplast constituents, indicative of the common origin of amyloplasts and chloroplasts.

\section{Signaling (Proteins \#|30-13I)}

Inositol phosphate phosphatase (\#130) and inositol monophosphatase (\#131) are typically involved in signal transduction although in plants they may also be involved in metabolism of inositol for other purposes. Both had predicted plastid transit peptides and are found in chloroplasts (Table 4).

\section{Substrate transport (Proteins \# 132-135)}

Protein channels and transporters are required to move molecules in and out of the amyloplast, crossing the outer and inner membranes. Only four were detected, the putative ADP-glucose transporter (\#134), two ABC-type transporters $(\# 132,133)$ and one amino acid selective channel protein (\#135) (Table 4). Two had predicted plastid target peptides and two had predictions of "other", not unexpected for membrane proteins that would be inserted into the envelope membranes rather than transported through them. This is a small number of transport proteins, considering the need to transport minerals such as $\mathrm{Pi}, \mathrm{Fe}$ and $\mathrm{SO}_{4^{-}}$, carbohydrates, folate, amino acids, vitamins and cofactors in and out of the amyloplast [26], and it is likely that many more wheat amyloplast membrane transport proteins will be discovered with improved techniques and increased sequence information. For example, 16 putative plastidic phosphate translocator genes were identified in a study of the Arabidopsis genome [81]. Kleffman et al. [82] identified 118 proteins with potential roles in transport in a proteomics study of Arabidopsis chloroplasts. They discovered many more transport proteins using a shotgun approach than by using the 2D-gel approach of [6]. The proteins and genes for all plastid transport proteins may not have been identified yet, in part because of the difficulty of measuring transport by membrane proteins to verify their function. Thus even the putative ADPglucose transporter has not actually been proven to transport ADP-glucose [83].

\section{Protein synthesis, import, assembly and processing (Proteins \#136-163)}

Twenty-eight proteins were involved in protein synthesis, import assembly, folding, or turnover and represent $16 \%$ of the proteins assigned to the amyloplast (Table 4).

\section{Ribosomal proteins (Proteins \#136-142)}

Seven proteins known to be associated with the chloroplast ribosomal complex were detected. All are encoded by nuclear DNA. Five were predicted to have plastid transit peptides, one had a prediction of plastid or mitochondrion, and one of plastid or "other". Plastid ribosomes are necessary for synthesis of proteins encoded by plastid DNA [80]. Only three such proteins were detected in this study (\#25, 122, 123). 


\section{Protein import (Proteins \#/43-148)}

Six proteins form the pores that cross the outer and inner plastid envelopes and facilitate the import of proteins synthesized on cytoplasmic ribosomes. The Toc-like proteins (\#146-148) are associated with the outer envelope and the Tic-like proteins (\#143-145) with the inner envelope $[84,85]$. Toc 34 (\#146) does not require a transit peptide for insertion into the outer envelope. Transit peptides were predicted for the other five proteins.

Assembly, folding, proteolysis and turnover (Proteins \# 149-163) Fifteen proteins required for protein synthesis and processing were detected. Ten were predicted to have plastid transit peptides and two to have mitochondrial transit peptides. The other three predictions were plastid/mitochondrion, "other"/plastid and "other". Functions of the chaperones and proteases that were detected in the amyloplast preparation are still being clarified. Nomenclature for this group of proteins can be confusing. The plastid Hsp90 family is equivalent to the Hsp100 family in other systems; some of the same proteins are also referred to as Clp proteins, some are chaperones that are also proteases, and vice versa [86-89]. Hydrolysis of ATP by the ClpC complex (below) is thought to provide energy for import of the proteins $[86-88,90]$. Binding by chaperones may also provide the driving force for import [81,82].

The Clp proteins form a chaperone complex that helps drive import of proteins into the plastid, cleave the transit peptide, and recycle plastid components $[86,89]$. The Clp protease complex may be the plastid equivalent of the proteasome [88]. An important role in green plastids is chlorophyll degradation and turnover. In amyloplasts it might be involved in regulating enzyme activity through selective degradation of plastid enzymes [86]. Clp protease holoenzymes in plastids from green and non-green tissue are reportedly composed of an identical set of 11 Clp proteins [88] of which three were identified in the amyloplast preparation (\#152-154). The rice and Arabidopsis homologs of proteins \#152 and \#153 were annotated ClpA-like, but Clp-A is not found in plants. A BLAST search of these homologs against the NCBI green plant database indicated that they were probably members of the ClpC family.

There are only a few records in NCBI for a plant protein sequence matching the putative amino peptidase $\mathrm{C}$, or acyl-peptide hydrolase (\#149). These are for a rice gene and an Arabidopsis homolog of bacterial prolyl oligopeptidase. Also, little information was available for the $20 \mathrm{kDa}$ chloroplast chaperonin (\#150). The oligopeptidase (\#156) cleaves the target peptide into amino acids so they may be recycled [90]. The plastid-lipid associated protein (\#160) may function in thylakoid turnover in green plastids. The zinc metallopeptidase (\#163) may be involved in removing the targeting peptide from proteins that are imported from the cytoplasm $[87,90]$.

\section{Plastid division (Proteins \# I 64- 165)}

Only two proteins involved in plastid division were detected (Table 4). FtsZ (\#164) and Arc6 (\#165) form part of a ring-like structure that constricts the plastid during division [85,91]. These may be important in pinching off amyloplast sections containing small B-type starch granules that form after the large A-type granules [28].

Plastid proteins of unknown function (Proteins \# I 66- I 78) Only 13 of the predicted amyloplast proteins were of unknown function (Table 4). Of these, peptides from 10 proteins matched gene products from rice or Arabidopsis that were of unknown function but were annotated as plastid proteins in the NCBI database and encoded transit peptides predicted to target the protein to the plastid. The predicted target sequence for \#172 was mitochondrial or plastid but the Arabidopsis homolog is annotated as chloroplast. Three proteins (\#174-176) were assigned to this category based only on prediction of a plastid transit peptide and presence in the amyloplast fraction. Although five of the unknown proteins had some functional information, it was insufficient to assign them roles.

\section{Plastid or mitochondrial proteins of unknown function (Proteins \#/80-182)}

Peptides from an additional three proteins (\#180-182) matched gene products that were not annotated as to function or cellular location but had transit peptides with good scores for both plastid and mitochondrion (Table 4).

\section{Missing Proteins}

Because of the large dynamic range of protein amount in biological tissues, proteomic studies mainly detect those abundant proteins for which tryptic digestion produces peptides within the optimal size range for analysis [92]. Tissue fractionation improves the range of proteins detected, and many proteins were detected in the amyloplast fraction that were not previously identified in a general extract of salt-soluble proteins. However, the 178 predicted amyloplast proteins are likely to be those that are most abundant and/or amenable to the method of analysis. For example, proteins of 1-C metabolism [54], serine acetyl transferase [58] and enzymes of NAD synthesis [66] are not abundant and are difficult to detect. Few proteins involved in signal transduction were detected, probably because they are less abundant. More transport proteins might be identified by a different technique [82].

Most pathways detected in this study are located exclusively in plastids and are essential for endosperm metabolism, including most steps in synthesis of amino acids, 
fatty acids, biliverdin and vitamins. Therefore, enzymes required for these pathways are likely to be present in the amyloplast even if they were not detected. For example the enzymes of the chorismate pathway for synthesis of phenylalanine and tryptophan seem to be required, since there is net synthesis of these amino acids in endosperm. In other cases, failure to detect a protein may indicate its absence from amyloplasts, as in the example of fructose bisphosphatase that is not required because wheat amyloplasts do not utilize triose phosphates [46]. Considerable study will be required to map the multi-compartment pathways such as those for sulfur metabolism or for salvage and de-novo synthesis of the nucleic acids.

\section{Accuracy of the target predictions}

In many cases, the enzymes that were detected are from pathways specific to plastids, and the Target P prediction was in agreement with that knowledge. Similarly, in many cases the Target $\mathrm{P}$ prediction for a non-plastid compartment was in agreement with general knowledge about proteins determined to be contaminants, such as the storage proteins, Ras-related proteins of the ER and secretory system, and cytoplasmic ribosomal proteins (Additional file 1). In some cases, however, the evidence is not conclusive. Algorithms for prediction of organelle targeting are not perfect, as discussed in detail in [93]. Similar proteins may be targeted to different organelles [94] and in some cases single genes encode proteins targeted to more than one organelle [95]. In addition, genomic or cDNA sequences for many of the wheat proteins were not available, so many target $P$ predictions were based on related genes, mainly from rice. Thus it is possible that a wheat protein was encoded by a gene for a plastid-specific protein but the homolog was predicted to be non-plastid or vice versa. Thus these assignments should be treated with caution.

\section{Further directions}

To obtain higher grain yield with higher protein content and improve yield as temperatures rise it will be important to understand how the interconnected metabolic pathways of the amyloplast are regulated. Barneix [7] suggests that protein accumulation may be limited by remobilization and transport to the grain, and Mechin et al. [47] propose a key role for the cytoplasmic protein, pyruvate orthophosphate dikinase. However, as the carbon, nitrogen and sulfur building blocks that enter the grain are converted to starch and protein, many of the essential metabolic pathways that control these processes are within the amyloplast and may also play a roll in the tradeoff between yield and protein content. A number of key enzymes may be regulated by thioredoxin [31] and other regulatory mechanisms should be explored.
Multiple approaches are needed for further study of endosperm amyloplast development, composition, metabolism and regulation. A proteomics study is valuable in predicting the plastid location of specific gene products. However, this study was limited to the 10 to 12 DPA window in grain development when sufficient endosperm was available, starch granules were small, and little storage protein had accumulated. It is difficult to isolate amyloplasts free of the extensive network of ER used for storage protein biosynthesis, and after 15 DPA the accumulated starch and protein make it difficult to isolate amyloplasts at all. Techniques such as immunochemical localization or targeting of GFP-fusion proteins would be useful to study later stages in grain development and to provide additional proof of amyloplast localization. A detailed metabolomic study of the fluxes through various pathways is essential to evaluate their significance. Gene expression can be followed throughout grain-fill by using the proteomics data to identify candidate genes to follow in a transcriptomic study. A multidimensional metabolic map for the endosperm would take into account key sites of regulation in the amyloplast, cytoplasm, mitochondria and other organelles as grain-fill progresses.

\section{Conclusion}

Cereal endosperm is a heterotrophic tissue that is highly specialized for accumulation of starch and protein. The wheat grain imports a limited assortment of molecular building blocks from the phloem. Subsequently the imported sucrose, glutamine, and a few other amino acids are transformed into the array of amino acids, lipids, nucleic acids and carbohydrates needed to sustain the intense accumulation of starch and protein in the developing grain. Amyloplasts play a central role in this process. Until recently they have been discussed mainly in terms of their role in starch biosynthesis, whereas their role in synthesis of other endosperm components has been ignored. This study presents evidence for the amyloplast location of at least 18 essential metabolic pathways. Early in grain development, the amyloplasts are large organelles with outer and inner envelope membranes surrounding an extensive matrix and a small starch grain. Research has centered on enzymes associated with the starch granule, but we propose that the matrix is also the site of significant metabolic activity during grain fill.

The wheat endosperm produces the starch and protein that become the bread, pasta, and numerous other foods that supply a large percent of the calories in the human diet. Although most genes for plastid proteins are now encoded in the nucleus, they seem to have originated from the original symbiotic organism that became the first chloroplast $[78,82,85]$. That cyanobacterial symbiont is the ultimate source of many of the key enzymes required for cereal grain food production. 


\section{Methods}

Proteomics data were obtained by Balmer et al. [6]. Amyloplasts were prepared from endosperm at 10-12 DPA, separated into soluble and membrane fractions, and analyzed by two-dimensional gel electrophoresis. Tandem MS/MS spectra were used to interrogate three databases of wheat ESTs and contigs [35-37] as well as the NCBI nonredundant green plant database, excluding rice and Arabidopsis [34]. The peptides that were identified by tandem MS/MS are listed in a supplementary table in Balmer et al. [6]. The complete data are now available as two XML files [96]. To view the data, ftp the XML file to your own computer, access the GPM viewer at the GPM web site [97] and use the "view saved xml file" function to browse and find the XML file and open in it in GPM. The protein of interest can be found within the XML file by searching with the sequence identifier given in Additional file 1.

For this paper, the peptides predicted by [6] were used to interrogate the 2007 version of the NCBI nonredundant green plant protein and translated nucleotide databases [34] using the pBLASTn algorithm with a setting of Expect threshold of 20000, word size 2, Matrix Pam 30, Gap cost Existence: 2, Extension: 1 [40]. For each protein, the closest homolog with a complete $\mathrm{N}$-terminal sequence was identified. The Target-P algorithm was used to analyze the first 200 amino acids of the $\mathrm{N}$-terminal sequence to determine whether a transit peptide was predicted $[41,98]$. Database information about the cellular location of homologs from additional species was also evaluated. The pBLAST algorithm above was used to interrogate the NCBI EST database, and one typical wheat EST representing each protein was selected, unless the gene or cDNA sequence picked from the NCBI nonredundant database was from Triticum aestivum.

Plastid enzymes were grouped into metabolic pathways, based on pathways shown in the ExPASy biochemical pathways $[99,100]$, information from BRENDA $[101,102]$, and many references cited in the text. The most recent EC number and preferred enzyme name was assigned based on information in the latest version of BRENDA 2007.1. Protein and gene databases are constantly being updated. To maintain consistency between this paper and the data in [6] the Additional file 1 includes the same number from the Swiss-Prot database [103] that was used in [6]. Some identifications have changed however.

\section{Abbreviations}

DPA: days after anthesis.

\section{Additional material}

\section{Additional file 1}

Detailed proteomic data for proteins detected in the amyloplast fraction. The table gives the enzyme names, EC number currently listed as preferred in the BRENDA enzyme database [,], identification numbers for the contig or the NCBI gi number for the sequence identified in the original MS/ MS study, the Swiss-Prot []] number used in [6], the number of nonredundant peptides identified, the GenBank accession number for the most closely related homolog in the NCBI nonredundant data base [34] for which a complete protein sequence could be deduced, the predicted organelle and score from the Target-P program $[41,97]$, the known cellular location(s) of the protein in plants, and indicates which proteins were detected in an endosperm salt-soluble extract [42] or identified as thioredoxin-binding in [31].

Click here for file

[http://www.biomedcentral.com/content/supplementary/14712229-8-39-S1.pdf]

\section{Additional file 2}

Figures 2-17.

Click here for file

[http://www.biomedcentral.com/content/supplementary/14712229-8-39-S2.zip]

\section{Additional file 3}

Figure 2-17. Detailed hypothetical pathways mapping enzymes of biosynthetic pathways in the wheat endosperm amyloplast.

Click here for file

[http://www.biomedcentral.com/content/supplementary/14712229-8-39-S3.pdf]

\section{Acknowledgements}

Funding is from USDA Agricultural Research Service CRIS PROJECT 532543000-026-00D. The original proteomics data all refer to the work of Yves Balmer, Bob Buchanan, Frances Dupont, William Hurkman, and William Vensel reported in [6]. Thanks to Susan Altenbach for reading the manuscript and providing helpful suggestions. Mention of a specific product name by the United States Department of Agriculture does not constitute an endorsement and does not imply a recommendation over other suitable products.

\section{References}

I. Baker DA, Young DL, Huggins DR, Pan WL: Nitrogen management. Economically optimal nitrogen fertilization for yield and protein in hard red spring wheat. Agron J 2004, 96: I I6-123.

2. Bhatia $C R$, Rabson R: Bioenergetic considerations in cereal breeding for protein improvement. Science 1976, 194:|4|8-|42|.

3. Fowler DB: Crop nitrogen demand and grain protein concentration of spring and winter wheat. Agron J 2003, 95:260-265.

4. Simmonds NW: The relation between yield and protein in cereal grain. J Sci Food Agric 1995, 67:209-315.

5. Oury F-X, Godin C: Yield and grain protein concentration in bread wheat: how to use the negative relationship between the two characters to identify favourable genotypes? Euphytica 2007, 157:45-57.

6. Balmer Y, Vensel WH, DuPont FM, Buchanan BB, Hurkman WJ: Proteome of amyloplasts isolated from developing wheat endosperm presents evidence of broad metabolic capability. J Exp Botany 2006, 57:1591-1602. 
7. Barneix A: Physiology and biochemistry of source-regulated protein accumulation in the wheat grain. J Plant Physiol 2007, 164:581-590.

8. Jenner CF: The physiology of starch and protein deposition in the endosperm of wheat. Aust J Plant Physiol I991, I 8:2 I I-226.

9. Martre P, Jamieson PD, Semenov MA, Zyskowski RF, Porter JR, Triboi $\mathrm{E}:$ Modelling protein content and composition in relation to crop nitrogen dynamics for wheat. Eur J Agron 2006, 25: I 38-I 54.

10. Altenbach SB, Dupont FM, Kothari KM, Chan R: Temperature, water and fertilizer influence the timing of key events during grain development in a US spring wheat. J Cereal Sci 2003 , 37:9-20.

II. Dupont FM, Hurkman WJ, Vensel WH, Chan R, Lopez R, Tanaka CK, Altenbach SB: Differential accumulation of sulfur-rich and sulfur-poor wheat flour proteins is affected by temperature and mineral nutrition during grain development. J Cereal Sci 2006, 44:101-II2.

12. Rharrabti Y, Elhani S, Martos-Nunez V, Garcia del Moral L: Protein and lysine content, grain yield and other technological traits in durum wheat under Mediterranean conditions. J Agric Food Chem 200I, 49:3802-3807.

13. Banziger M, Feil B, Stamp P: Competition between nitrogen accumulation and grain growth for carbohydrates during grain filling of wheat. Crop Sci 1994, 34:440-446.

14. Brown BD, Petrie S: Irrigated hard winter wheat response to fall, spring, and late season applied nitrogen. Field Crops Res 2006, 96:260-268.

15. Hawker JS, Jenner CF: High temperature affects the activity of enzymes in the committed pathway of starch synthesis in developing wheat endosperm. Aust J Plant Physiol 1993, 20:197-209.

16. Hurkman WJ, McCue KF, Altenbach SB, Korn A, Tanaka CK, Johnson EL, Bechtel DB, Anderson OD, DuPont FM: Expression of genes for starch biosynthesis is regulated by high temperature in developing wheat endosperm. Plant Sci 2003, I 64:873-88I.

17. Emes CG, Bowsher C, Hedley M, Burrell M, Scrase-Field ESF, Tetlow IJ: Starch synthesis and carbon partitioning in developing endosperm. J Exp Bot 2003, 54:569-575.

18. Fisher DB, Gifford RM: Accumulation and conversion of sugars by developing wheat grains VI. Gradients along the transport pathway from the peduncle to the endosperm cavity during grain filling. Plant Physiol 1986, 82: 1024-1030.

19. Fisher DB, McNichol PK: Amino acid composition along the transport pathway during grain filling in wheat. Plant Physiol 1986, 82:1019-1023.

20. Ugalde TD, Jenner CF: Substrate gradients and regional patterns of dry matter deposition within developing wheat endosperm. II. Amino acids and proteins. Plant Physiol 1990, 1 7:377-394.

21. Anderson JW, Fitzgerald MA: Physiological and metabolic origin of sulphur for the synthesis of seed storage proteins. I Plant Physiol 200I, I 58:447-456.

22. Bourgis F, Roje S, Nuccio ML, Fisher DB, Tarczynski MC, Li C, Herschbach C, Rennenberg H, Pimenta MJ, Shen T, Gage DA, Hanson $A D$ : S-methylmethionine plays a major role in phloem sulfur transport and is synthesized by a novel type of methyltransferase. Plant Cell I999, I I:|485-|497.

23. Kopriva S: Regulation of sulfate assimilation in Arabidopsis and beyond. An Bot 2006, 97:479-495.

24. Edelman J, Shibko SI, Keys AJ: The role of the scutellum of cereal seedlings in the synthesis and transport of sucrose. J Exp Bot 1959, 10:178-89.

25. Smart MG, O'Brien MG: The development of the wheat embryo in relation to the neighbouring tissues. Protoplasma 1983 | | 4: 1-13.

26. Lunn JE: Compartmentation in plant metabolism. J Exp Bot 2007, 58:35-47.

27. Neuhaus HE, Emes MJ: Nonphotosynthetic metabolism in plastids. Annu Rev Plant Physiol Plant Mol Biol 2000, 5 I : I I I- | 40.

28. Bechtel DB, Wilson JD: Amyloplast formation and starch granule development in hard red winter wheat. Cereal Chem 2003, 80: $175-183$

29. Langeveld SMJ, van Wijk R, Stuurman N, Kijne JW, de Pater S: B-type granule containing protrusions and interconnections between amyloplasts in developing wheat endosperm revealed by transmission electron microscopy and GFP expression. J Exp Bot 2000, 5 I:|357-|36|.

30. Andon NL, Hollingworth S, Koller A, Greenland AJ, Yates JR, Haynes PA: Proteomic characterization of wheat amyloplasts using identification of proteins by tandem mass spectrometry. Proteomics 2002, 2: I I56- I I68.

31. Balmer Y, Vensel WH, Cai N, Manierie W, Schurmann P, Hurkman WJ, Buchanan BB: A complete ferredoxin-thioredoxin system regulates fundamental processes in amyloplasts. Proc Nat Acad Sci USA 2006, 103:2988-2993.

32. AraCyc Database [http://www.arabidopsis.org/biocyc/index.jsp]

33. RiceCyc Database [http://www.gramene.org/pathway/]

34. NCBI National Center for Biotechnology Information databases [http://www.ncbi.nlm.nih.gov/]

35. wEST Database [http://wheat.pw.usda.gov/wEST/]

36. HarvEST Database [http://harvest.ucr.edu/]

37. NCBI Triticum aestivum Unigene Database ftp.ncbi.nih.gov/repository/UniGene/]

38. Altenbach SB, Kothari KM: Omega gliadin genes expressed in Triticum aestivum cv Butte 86: effects of post-anthesis fertilizer on transcript accumulation during grain development. J Cereal Sci 2007, 46: I69-I77.

39. Altenbach SB, Kothari KM, Tanaka CK, Hurkman W]: Expression of 9-kDa non-specific lipid transfer protein genes in developing wheat grains is enhanced by high temperatures but not by post-anthesis fertilizer. J Cereal Sci 2007.

40. BLAST Basic Local Alignment Search Tool [http:// www.ncbi.nlm.nih.gov/BLAST/]

4I. Target P. Prediction of subcellular location of eukaryotic proteins [http://www.cbs.dtu.dk/services/TargetP/]

42. Vensel WH, Tanaka CK, Cai N, Wong JH, Buchanan BB, Hurkman WJ: Developmental changes in the metabolic protein profiles of wheat endosperm. Proteomics 2005, 5:|594- |6 I I.

43. Plaxton WC: The organization and regulation of plant glycolysis. Annu Rev Plant Physiol Plant Mol Biol 1996, 47:|85-2I4.

44. Tyson RH, ap Rees T: Starch synthesis by isolated amyloplasts from wheat endosperm. Planta 1988, I75:33-38.

45. Wiese A, Groner F, Sonnewald U, Deppner H, Lerchl J, Hebbeker U, Flugge U-I, Weber A: Spinach hexokinase I is located in the outer envelope membrane of plastids. FEBS Lett 1999 461 : $13-18$.

46. Entwistle G, ap Rees T: Lack of fructose- I,6-bisphosphatase in a range of higher plants that store starch. Biochem J 1990 , 27 I:467-4.

47. Mechin V, Thevenot C, Le Guilloux M, Prioul J-L, Damerval C: Developmental analysis of maize endosperm proteome suggests a pivotal role for pyruvate orthophosphate dikinase. Plant Physiol 2007, I 43:1203-1219.

48. Tovar-Mendez A, Miernyk JA, Randall DD: Regulation of pyruvate dehydrogenase complex activity in plant cells. Eur J Biochem 2003, 270: 1043-1049.

49. Drincovich MF, Casati P, Carlos P, Andreo S: NADP-malic enzyme from plants: a ubiquitous enzyme involved in different metabolic pathways. FEBS Lett 200I, 490: I-6.

50. Denyer K, Dunlap F, Thorbjornsen T, Keeling P, Smith AM: The major form of ADP-glucose pyrophosphorylase in maize endosperm is extra-plastidial. Plant Physiol 1996, I I 2:779-785.

51. Baldwin PM: Starch granule-associated proteins and polypeptides: a review. Starch/Stärke 200I, 53:475-503.

52. Okubara PA, Pawlowski K, Murphy TM, Berry AM: Symbiotic root nodules of the actinorhizal plant Datisca glomerata express rubisco activase mRNA I. Plant Physiol 1999, I 20:4 | I-420.

53. Schwender J, Goffman F, Ohlrogge JB, Shachar-Hill Y: Rubisco without the Calvin cycle improves the carbon efficiency of developing green seeds. Nature 2004, 432:779-782.

54. Hanson $A D$, Roje $S$ : One-carbon metabolism in higher plants. Annu Rev Plant Physiol Plant Mol Biol 2001, 52:1 19-37.

55. Basset G, Quinlivan EP, Ziemak MJ, Díaz de la Garza R, Fischer RM, Schiffmann S, Bacher A, Gregory JF, Hanson AD: Folate synthesis in plants: The first step of the pterin branch is mediated by a unique bimodular GTP cyclohydrolase I. Proc Natl Acad Sci USA 2002, 99: 12489-12494

56. Schmid J, Amrhein N: Molecular organization of the shikimate pathway in higher plants. Phytochemistry 1995, 39:737-749. 
57. Azevedo RA, Lancien M, Lea PJ: The aspartic acid metabolic pathway, an exciting and essential pathway in plants. Amino Acids 2006, 30: |43-162.

58. Wirtz $M$, Droux $M$ : Synthesis of the sulfur amino acids: cysteine and methionine. Photosynthesis Res 2005, 86:345-362.

59. Martin MN, Tarczynski MC, Shen B, Leustek T: The role of 5'-adenylylsulfate reductase in controlling sulfate reduction in plants. Photosynthesis Res 2005, 86:309-303.

60. Ho C-L, Saito K: Molecular biology of the plastidic phosphorylated serine biosynthetic pathway in Arabidopsis thaliana. Amino Acids 200I, 20:243-259.

61. Rebeille F, Ravanela S, Jabrina S, Douce R, Strorozhenkob S, Van Der Straeten D: Folates in plants: biosynthesis, distribution, and enhancement. Physiol Plantarum 2006, I 26:30-342.

62. Martin A, Lee J, Kichey T, Gerentes D, Zivy M, Tatou C, Dubois F, Balliau T, Valot B, Davanture M, Terce' Laforgue E, Quillere' I, Coque M, Gallais A, Gonzalez-Moro M, Bethencourt L, Habash D, Lea P, Charcosse A, Pere P, Murigneux A, Sakakibara H, Edwards KJ, Bertrand Hirel B: Two cytosolic glutamine synthetase isoforms of maize are specifically involved in the control of grain production. Plant Cell 2006, 18:3252-3274.

63. Aral B, Kamoun P: The proline biosynthesis in living organisms. Amino Acids 1997, I3: 189-217.

64. Stasolla C, Katahira R, Thorpe TA, Ashihara $\mathrm{H}$ : Purine and pyrimidine nucleotide metabolism in higher plants. J Plant Physiol 2003, 160:1271-1295

65. Atkins CA, Smith PMC, Sto PJ: Reexamination of the intracellular localization of de novo purine synthesis in cowpea nodules. Plant Physiol 1997, I3:127-135.

66. Katoh A, Uenohara K, Akita M, Hashimoto T: Early steps in the biosynthesis of NAD in Arabidopsis start with aspartate and occur in the plastid. Plant Physiol 2006, I 4 I:85 I-857.

67. Kannangara CG, Gough SP, Bryuant P, Hoober JK, Kahn A, von Wetstein D: tRNAglu as a cofactor in $\delta$-aminolevulinate biosynthesis: steps that regulate chlorophyll synthesis. Trends Biol Sci 1988, I 3:139-143.

68. Yaronskaya E, Vershilovskaya I, Poers Y, Alawady AE, Averina N, Ala wady A, Grimm B: Cytokinin effects on tetrapyrrole biosynthesis and photosynthetic activity in barley seedlings. Planta 2006, 224:700-709.

69. Laule O, Furholz A, Chang H-S, Zhu T, Wang X, Heifetz PB, Gruissem W, Lange M: Crosstalk between cytosolic and plastidial pathways of isoprenoid biosynthesis. Proc Natl Acad Sci USA 2003. I 00:6866-687I.

70. Della Penna D, Pogson B]: Vitamin synthesis in plants: tocopherols and carotenoids. Annu Rev Plant Biol 2006, 57:7 I I-38.

7I. Moise AR, Lintig J, Palczewski K: Related enzymes solve evolutionarily recurrent problems in the metabolism of carotenoids. Trends Plant Sci 2005, I 0:1360-1385.

72. Bacher A, Eberhardt S, Fischer M, Kis K, Richter G: Biosynthesis of vitamin B2 (Riboflavin). Annu Rev Nutr 2000, 20:153-67.

73. Belanger FC, Leustek T, Chu B, Kriz A: Evidence for the thiamine biosynthetic pathway in higher-plant plastids and its developmental regulation. Plant Mol Biol 1995, 29:809-82I.

74. Hanke GT, Okutani S, Satomi Y, Takao T, Suzuki A, Hase T: Multiple iso-proteins of FNR in Arabidopsis: evidence for different contributions to chloroplast function and nitrogen assimilation. Plant Cell Environ 2005, 28: I |46- I I 57.

75. Allen RD: Dissection of oxidative stress tolerance using transgenic plants. Plant Physiol 1995, 107: 1049-1054.

76. Shigeoka S, Ishikawa T, Tamoi M, Miyagawa Y, Takeda T, Yabuta $Y$ Yoshimura K: Regulation and function of ascorbate peroxidase isozymes. J Exp Bot 2002, 53:1305-1319.

77. Brehelin C, Meyer EH, de Souris J-P, Bonnard G, Meyer Y: Resemblance and dissemblance of Arabidopsis type II peroxiredoxins: similar sequences for divergent gene expression, protein localization, and activity. Plant Physiol 2003, I 32:2045-2057.

78. Harris EH, Boynton JE, Gillham NW: Chloroplast ribosomes and protein synthesis. Microbiol Rev 1994, 58:700-754.

79. Yamaguchi K, Subramanian AR: The Plastid ribosomal proteins. Identification of all the proteins in the 505 subunit of an organelle ribosome (chloroplast). I Biol Chem 2000, 275:28466-28482.

80. Zerges W: Translation in chloroplasts. Biochimie 2000, 82:583-601.
8I. Knappe S, Flugge U, Fischer K: Analysis of the plastidic phosphate translocator gene family in Arabidopsis and identification of new phosphate translocator-homologous transporters, classified by their putative substrate-binding site. Plant Physiol 2003, I 3 I: I I 78- I 190

82. Kleffmann T, Russenberger D, von Zychlinski A, Christopher W, Sjolander K, Gruissem W, Baginsky S: The Arabidopsis thaliana chloroplast proteome reveals pathway abundance and novel protein functions. Curr Biol 2004, I4:354-362.

83. Bowsher CG, Scrase-Field EFAL, Esposito S, Emes MJ, Tetlow II: Characterization of ADP-glucose transport across the cereal endosperm amyloplast envelope. J Exper Bot 2007, 58: $1321-1332$.

84. Kuchler M, Soll J: From nuclear genes to chloroplast localized proteins. Plant Sci 2001, 16 I:379-389.

85. Lopez-Juez E: Plastid biogenesis, between light and shadows. J Exp Bot 2007, 58: | |-26.

86. Sakamoto $\mathrm{W}$ : Protein degradation machineries in plastids. Annu Rev Plant Biol 2006, 57:599-62I.

87. Krishna P, Gloor G: The Hsp90 family of proteins in Arabidopsis thaliana. Cell Stress Chaperones 200I, 6:238-246.

88. Peltier J-B, Ripoll DR, Friso G, Rudella A, Cai Y, Ytterberg J, Giacomelli L, Pillardy J, van Wijk KJ: Clp Protease complexes from photosynthetic and non-photosynthetic plastids and mitochondria of plants, their predicted three-dimensional structures, and functional implications. I Biol Chem 2004 279:4768-478।

89. Constan D, Froehlich JE, Rangarajan S, Keegstra K: A stromal hsp 100 protein is required for normal chloroplast development and function in Arabidopsis. Plant Physiol 2004, I36:3605-3615.

90. Richter S, Zhong R, Lamppa G: Function of the stromal processing peptidase in the chloroplast import pathway. Physiol Plant 2005, I 23:362-368.

91. Aldridge C, Maple J, Møller SG: The molecular biology of plastid division in higher plants. J Exp Bot 2005, 56: 106 I- 1077.

92. Mallick P, Schirle M, Chen SS, FloryI MR, Lee H, Martin D, Ranish J, Raught B, Schmitt R, Werner T, Kuster B, Aebersold R: Computational prediction of proteotypic peptides for quantitative proteomics. Nature Biotech 2007, 25:|25-131.

93. van Wijk KJ: Plastid Proteomics. Plant Physiology and Biochemistry 2004, 42:963-977.

94. Kruger NJ, von Schaewen A: The oxidative pentose phosphate pathway: structure and organization. Curr Opin Plant Biol 2003 6.236-246.

95. Wall MK, Mitchenall LA, Maxwell A: Arabidopsis thaliana DNA gyrase is targeted to chloroplasts and mitochondria. Proc Nat Acad Sci USA 2004, 1 $01: 7821$-7826.

96. [http://wheat.pw.usda.gov/pubs/2008/dupont]

97. The Global Proteome Machine Organization Proteomics Database and Open Source Software [http://www.thegpm.org/ ]

98. Emanuelsson $\mathrm{O}$, Nielsen $\mathrm{H}$, Brunak S, von Heijne G: Predicting subcellular localization of proteins based on their $\mathbf{N}$-terminal amino acid sequence. J Mol Biol 2000, 300:1005-1016.

99. EXPASY Biochemical Pathways Database [http:// www.expasy.ch/cgi-bin/search-biochem-index]

100. Gasteiger E, Gattiker A, Hoogland C, Ivanyi I, Appel RD, Bairoch A: ExPASy: the proteomics server for in-depth protein knowledge and analysis. Nucleic Acids Res 2003, 3 I:3784-3788.

I0I. Brenda. The comprehensive enzyme database system [http://www.brenda-enzymes.info/]. Version 7.I

102. Schomburg I, Chang A, Ebeling C, Gremse M, Heldt C, Huhn G, Schomburg D: BRENDA, the enzyme database: updates and major new developments. Nucleic Acids Res 2004, I:D43 I-3.

103. Swiss Prot database (now incorporated into the Uni Prot database system) [http://www.ebi.ac.uk/uniprot/] 